\title{
2-Methoxyestradiol Attenuates Autophagy Activation After Global Ischemia
}

\author{
Xiao-Yu Xin, Jing Pan, Xiao-Qiang Wang, Jian-Fang Ma, Jian-Qing Ding, \\ Guo-Yuan Yang, Sheng-Di Chen
}

\begin{abstract}
Background: Hypoxia inducible factor 1 (HIF-1) is a key transcriptional factor activated during cerebral ischemia, which regulates a great number of downstream genes, including those associated with cell death. In the present study, we aimed to test the hypothesis that post-ischemic HIF-1 $\alpha$ up-regulation might promote autophagy activation; thereby, HIF-1 $\alpha$ inhibitor $2 \mathrm{ME} 2$ might prevent neurons from ischemic injury through inhibiting autophagy. Methods: Global ischemia was induced using the four-vessel occlusion model (4-VO) in Sprague-Dawley rats (male, 250-280g). 2-Methoxyestradiol (2ME2, 5mg/kg, i.p.) was administrated to down-regulate HIF-1 $\alpha$ expression. Post-ischemic beclin-1 and LC3 protein expression was determined at different time points through Western blot assay. Neuronal injury was determined by cresyl violet staining and TUNEL staining in coronal histological sections. Results: The expression of beclin-1 and the ratio of LC3-II/LC3-I increased significantly at 12 and 24 h after ischemia. 2ME2 could remarkably inhibit the up-regulation of beclin-1 and the increase of LC3-II/LC3-I ratio during reperfusion. Moreover, 2ME2 and 3-MA exhibited powerful protective effects against ischemic/reperfusion induced neuronal injury. Conclusions: This study confirmed that autophagy participated in post-ischemic neuronal injury. 2ME2, a HIF-1 $\alpha$ inhibitor, might significantly decrease autophagy activation after cerebral ischemia and relieve post-ischemic neuronal injury. Our findings demonstrate that autophagy could be a potential target for neuronal protection after cerebral ischemia.
\end{abstract}

RÉSUMÉ: Le 2-méthoxyestradiol atténue l'activation de l'autophagie après une ischémie globale : Contexte : Le facteur 1 induit par l'hypoxie (HIF-1) est un facteur transcriptionnel clé qui est activé pendant l'ischémie cérébrale et qui régule plusieurs gènes sous son contrôle, dont ceux qui sont associés à la mort cellulaire. Le but de cette étude était de vérifier l'hypothèse selon laquelle la régulation à la hausse de HIF-1 $\alpha$ post-ischémique pourrait promouvoir l'activation de l'autophagie. Le 2-méthoxyestradiol (2ME2), un inhibiteur de HIF-1 $\alpha$, pourrait donc protéger les neurones du dommage ischémique en inhibant l'autophagie. Méthode : Nous avons induit une ischémie globale au moyen du modèle d'occlusion de quatre vaisseaux (4-VO) chez des rats Sprague-Dawley mâles de 250 à $280 \mathrm{~g}$. Nous leur avons injecté par voie intrapéritonéale $5 \mathrm{mg} / \mathrm{kg}$ de $2 \mathrm{ME} 2$ afin de réguler à la baisse l'expression de HIF-1 $\alpha$. Nous avons mesuré l'expression des protéines beclin-1 et LC3 par buvardage Western à différents moments. Le dommage neuronal était déterminé par coloration au violet de crésyl et coloration TUNEL de coupes histologiques coronales. Résultats : L'expression de beclin1 et le ratio LC3-II/LC3-1 ont augmenté significativement 12 et 24 heures après l'ischémie. Le 2ME2 pouvait inhiber de façon importante la régulation à la hausse de beclin-1 et l'augmentation du ratio LC3II/LC3-1 pendant la reperfusion. De plus, le 2ME2 et le 3-MA ont eu des effets protecteurs puissants contre le dommage neuronal induit par l'ischémie/reperfusion. Conclusions : Cette étude confirme que l'autophagie contribue au dommage neuronal post-ischémique. Le 2ME2, un inhibiteur de HIF-1 $\alpha$, pourrait diminuer de façon importante l'activation de l'autophagie après l'ischémie cérébrale et minimiser le dommage neuronal post-ischémique. Nos observations démontrent que l'autophagie pourrait être une cible potentielle de protection neuronale après une ischémie cérébrale.

Can. J. Neurol. Sci. 2011; 38:631-638

Ischemic stroke remains a leading cause of death and disability around the world, with limited successful therapeutic strategies ${ }^{1}$. In the past decade, preventing neuronal damage to improve recovery has always been a focus in stroke research, which is still a promising target ${ }^{2}$. With regard to the major mechanisms of ischemic neuronal damage, early events such as oxidative stress, calcium overload, as well as excitotoxity, may rapidly result in neuronal necrosis in the infarct core; however, later events such as inflammation are relevant to programmed cell death in the penumbra ${ }^{3}$.

Apoptosis is a classic type I programmed cell death. Accompanied by the activation of caspases, the induction of apoptotic neuronal death is associated with proapoptotic factors such as Bad or Bax, and suppressed by anti-apoptotic factors such as Bcl-xL $\mathrm{L}^{4,5}$. Although apoptosis has been intensively

From the Department of Neurology and Institute of Neurology (XYX, JP, JFM, JQD,

SDC), Department of Neurosurgery (XQW), Ruijin Hospital, Shanghai Jiao Tong

University School of Medicine; Med-X Institute (GYY), Shanghai Jiao Tong

University, Shanghai, China.

Received November 4, 2010. Final Revisions Submitted March 7, 2011. Correspondence to: Sheng-Di Chen, Department of Neurology \& Institute of Neurology, Ruijin Hospital, Shanghai Jiao, Tong University School of Medicine, Shanghai 200025, China. 
studied in the field of ischemic stroke, few anti-apoptotic strategies have proven to be useful, indicating that other molecular pathways might be involved in post-ischemic neuronal death 6 .

Autophagy is a well-conserved mechanism activated in response to nutrient deprivation, which is a highly regulated process for degradation of macromolecules via the lysosomal system. Theoretically, autophagy may help promote cell survival, either by purging the cell of damaged organelles or toxic pathogens, or by regenerating metabolites for energy and growth during nutrient-limiting conditions. However, excess or prolonged autophagy may also promote cell death through excessive self-digestion and degradation of essential cellular constituents $^{7,8}$. Autophagic cell death is also known as type II programmed cell death. Despite the presence of underlying crosstalk, autophagic cell death is different from apoptotic cell death not only in morphology but also in gene regulation. Although some previous studies have indicated autophagy activation following cerebral ischemia ${ }^{9,10}$, the underlying mechanism and its contribution to neuronal death after ischemic injury remain to be determined.

Hypoxia inducible factor 1 (HIF-1) is a heterodimeric transcriptional factor composed of a constitutively expressed HIF-1 $\beta$ subunit and an inducibly expressed HIF-1 $\alpha$ subunit. Under hypoxic conditions, because of inhibited ubiquitination, HIF- $1 \alpha$ may accumulate and dimerize with HIF-1 $\beta^{11}$; then, activating transcription of a broad range of hypoxia-responsive genes, including vascular endothelial growth factor (VEGF), erythropoietin (EPO), glucose tranporter 1, and glycolytic enzymes $^{12}$. However, some important evidence recently suggested that HIF-1 might also contribute to the execution of programmed cell death. For example, HIF-1 may interact with Bcl-2 family members such as Bcl-2/adenovirus E1B $19 \mathrm{kDa}$ interacting protein 3 (BNIP3) ${ }^{13}$; the later, an essential regulator in the autophagic pathway.

2-methoxyestradiol (2ME2) is a natural metabolite of estradiol, which has been widely used as an HIF-1 $\alpha$ inhibitor in other studies ${ }^{14-18}$. The present investigation was designed to clarify the possible relationship between HIF-1 up-regulation and autophagy activation following global cerebral ischemia in vivo. 2-methoxyestradiol was used to down-regulate HIF-1 $\alpha$ expression. We tested the hypothesis that $2 \mathrm{ME} 2$ might attenuate post-ischemic autophagic cell damage and minimize neuronal injury. We also compared the effects of $2 \mathrm{ME} 2$ with those of 3methyl-adenine (3-MA), which is an autophagy inhibitor, on post-ischemic neuronal injury.

\section{Materials AND Methods}

The animal protocol of the present study was evaluated and approved by Shanghai Experimental Animal Center, Chinese Academy of Science.

\section{Induction of global ischemia}

The experiments were performed on adult male SpragueDawley rats weighing 250-280g (Shanghai Experimental Animal Center, Chinese Academy of Science). Global cerebral ischemia was induced by four-vessel occlusion (4-VO) as described before $^{19}$. In brief, rats were anesthetized with $3 \%$ pentobarbital sodium (1.5ml/kg, intraperitoneally (i.p)); then, bilateral vertebral arteries were electrocauterized and common carotid arteries were exposed. Rats were allowed to recover for 24 hour (h) and fasted overnight. Thereafter, ischemia was induced by occluding bilateral common carotid arteries with aneurysm clips for 15 minutes (min). Rats which lost their righting reflex within 30 seconds (s) and whose pupils were dilated and unresponsive to light during ischemia were selected for the experiments. Rats with seizures were excluded. After $15 \mathrm{~min}$ of ischemia, aneurysm clips were removed for reperfusion. Throughout the operation, rectal temperature was maintained at $36.5-37.5^{\circ} \mathrm{C}$. Sham-operated animals underwent the same exposure procedures without clamping carotid arteries.

\section{Drug administration}

2ME2 or 3-MA (Sigma Aldrich, USA) was administrated half an hour before global ischemia. In 2ME2 group, the rats received $5 \mathrm{mg} / \mathrm{kg}$ 2ME2 intraperitoneally (i.p.), which was dissolved in $1 \%$ dimethyl sulfoxide (DMSO) to a final volume of $2 \mathrm{ml}$. In vehicle control group for 2ME2, the same volume of DMSO was injected (i.p.). For rats in 3-MA group, $5 \mu \mathrm{l} 0.9 \%$ saline (NS) containing $500 \mathrm{nmol} 3-\mathrm{MA}$ was administrated through intracerebralventricular injection (i.c.v.). During i.c.v. injection, the rats were placed on ear bars of a stereotaxic instrument under anaesthesia. Drug infusion into the left cerebral ventricle (from the bregma: anteroposterior: $-0.8 \mathrm{~mm}$; lateral: $1.5 \mathrm{~mm}$; depth: $3.5 \mathrm{~mm}$ ) was performed using a stepper-motorized microsyringe at the rate of $1 \mu \mathrm{l} / \mathrm{min}$. The same volume of vehicle was used as control.

\section{Protein sample preparation}

Rats were sacrificed under anaesthesia at different time points $(0,6,12,24$ and $72 \mathrm{~h}$ after reperfusion). The hippocampal regions were microdissected at $0^{\circ} \mathrm{C}$ and immediately frozen in liquid nitrogen. For Beclin-1 and LC3 detection, tissues were homogenized in ice-cold homogenization buffer which consists of $50 \mathrm{mM}$ HEPES ( $\mathrm{pH} 7.4), 150 \mathrm{mM} \mathrm{NaCl}, 12 \mathrm{mM} \beta$ glycerophosphate, $3 \mathrm{mM}$ dithiotheitol (DTT), $2 \mathrm{mM}$ sodium orthovanadate $\left(\mathrm{Na}_{3} \mathrm{VO}_{4}\right), 1 \mathrm{mM}$ EGTA, $1 \mathrm{mM} \mathrm{NaF}, 1 \mathrm{mM}$ phenylmethylsulfonyl fluoride (PMSF), $1 \%$ Triton X-100, and 5 $\mu \mathrm{g} / \mathrm{ml}$ each of leupeptin, pepstain $\mathrm{A}$ and aprotinin. The homogenates were centrifuged at $15,000 \mathrm{~g}$ for $30 \mathrm{~min}$ at $4^{\circ} \mathrm{C}$. Supernatants were collected and aliquots were stored at $-80^{\circ} \mathrm{C}$. For HIF-1 $\alpha$ analysis, nuclear proteins were extracted and examined. In brief, tissues were homogenized in $10 \mathrm{mM}$ HEPES (pH 7.9), $0.5 \mathrm{mM} \mathrm{MgCl}, 10 \mathrm{mM} \mathrm{KCl,} 0.1 \mathrm{mM}$ EDTA, $0.1 \mathrm{mM}$ EGTA, $50 \mathrm{mM} \mathrm{NaF}, 5 \mathrm{mM}$ DTT, $10 \mathrm{mM} \beta$-phosphoglycerol, 1 $\mathrm{mM} \mathrm{Na} \mathrm{VO}_{4}, 1 \%$ NP-40, $1 \mathrm{mM}$ benzamidine, $1 \mathrm{mM}$ PMSF and enzyme inhibitors. The homogenates were centrifuged at $800 \mathrm{~g}$ for $10 \mathrm{~min}$ at $4^{\circ} \mathrm{C}$; then, the nuclear pellets were extracted with 20 mM HEPES (pH 7.9), 20\% glycerol, $420 \mathrm{mM} \mathrm{NaCl}, 0.5 \mathrm{mM}$ $\mathrm{MgCl}_{2}, 1 \mathrm{mM}$ EDTA, $1 \mathrm{mM}$ EGTA, $1 \mathrm{mM}$ DTT and enzyme inhibitors for $30 \mathrm{~min}$ at $4^{\circ} \mathrm{C}$ with constant agitation. After centrifugation at $15,000 \mathrm{~g}$ for $30 \mathrm{~min}$ at $4^{\circ} \mathrm{C}$, the supernatants were removed and stored for use. The protein concentrations were determined by the method of Lowry with bovine serum albumin (BSA) as standard ${ }^{20}$. 


\section{Western blot assay}

Equal amounts of protein per lane $(50 \mu \mathrm{g})$ were loaded onto an $8 \%$ or $12 \%$ polyacrylamide gel and separated by electrophoresis. Then, proteins were electro-transferred onto a polyvinylidene difluoride (PVDF) membrane (Millipore, Billerica, MA, USA). The membrane was blocked with 5\% nonfat dry milk/0.1\% Tween-20 in Tris-buffered saline for $2 \mathrm{~h}$ at room temperature. Thereafter, the membrane was incubated with different primary antibodies overnight at $4^{\circ} \mathrm{C}$, such as mouse anti-HIF-1 $\alpha$ (1:500, Novus Biologicals), rabbit anti-beclin-1 (1:500, Sigma Aldrich, USA), rabbit anti-LC3 (1:800, Sigma Aldrich, USA), mouse anti-P53 (1:500, Santa Cruz), and goat anti-BNIP3 (1:500, Santa Cruz). Subsequently, the membrane was treated with appropriate horseradish peroxidase-labeled secondary antibodies for $2 \mathrm{~h}$ at room temperature. Immunoblots were probed using enhanced ECL chemiluminescence reagent (Amersham Bioscience). Band intensities were quantified by densitometric analyses using an AxioCam digital camera (Carl Zeiss GmbH, Jena, Germany) and a KS400 photo analysis system (version 3.0). Tata binding protein (TBP) or $\beta$-actin was used as internal control.

\section{Quantitative real-time polymerase chain reaction (PCR)}

Quantification of BNIP3 mRNA expression relative to $\beta$ actin was detected using real-time PCR. Total cellular RNA from the hippocampal region was extracted through Trizol reagent (Invitrogen). Reverse transcription was performed with a cDNA synthesis kit according to manufacturer's instruction (Takara). For quantitative SYBR Green real-time PCR $(2 \times$ SYBR Green Real-time PCR Master Mix, TOYOBO), the following primers were used: BNIP3 primer, sense: 5'-GCGCACAGCTACTCTCAGCA-3', antisense: 5'-GTCAGACGCCTTCCAA TGTAGA-3'; $\beta$-actin primer, sense: 5'-CATGTACGTTGCTATC CAGGC-3', antisense: 5'-CTCCTTAATG- TCACGCACGAT-3'. ABI 7900HT Sequence Detection System (Applied Biosystems) was applied and data were analyzed using ${ }^{\triangle} \triangle \mathrm{CT}$ method.

\section{Histological analysis}

Rats were anaesthesized five days after ischemia and transcardially perfusion-fixed with $4 \%$ paraformaldehyde in 0.1 $\mathrm{M}$ phosphate buffer (PBS). Brains were removed and post-fixed with the same fixation solution overnight at $4^{\circ} \mathrm{C}$. After embedded in paraffin, coronal sections $(6 \mu \mathrm{m})$ were prepared. Cresyl violet $(0.1 \%)$ was used for Nissle staining. Under light microscope, the sections were examined and neuronal density was expressed as the number of cells per $1 \mathrm{~mm}$ linear length of hippocampal CA1 pyramidal layer. To detect cell apoptosis, sections were stained with terminal deoxynucleotidyl transferase-mediated dUTP nick end labeling (TUNEL). The TUNEL-positive cells were expressed by POD with 3,3'-diaminobenzidine (DAB) according to the manufacturer's protocol (Roche).

\section{Statistics}

Five independent animals were sampled at each time point for Western blot assay and histology examination. Semiquantitative analysis of the bands was performed with the Image $\mathbf{J}$ analysis software (Version 1.30v; Wayne Rasband, NIH, USA). Semiquantitative data were expressed as mean \pm S.E.M. Differences between groups were compared by one-way analysis of variance (ANOVA), followed by the least significant difference (LSD) test or Newman-Keuls test. A probability value of $\mathrm{p}<0.05$ was considered statistically significant.

\section{RESULTS}

\section{HIF-1 $\alpha$ up-regulation and autophagy activation following global cerebral ischemia}

Since hippocampus is the most vulnerable region to transient global ischemia, we first examined HIF- $1 \alpha$ protein expression in this particular region at different time points. As shown in Figure 1 (A and D), the protein level of HIF-1 $\alpha$ increased rapidly after ischemia. As early as $6 \mathrm{~h}$ of reperfusion, significant upregulation of HIF-1 $\alpha$ was identified, which peaked at $12 \mathrm{~h}$ and did not decline until $24 \mathrm{~h}$ after ischemia.

Then, to explore the activation of autophagy after ischemia/ reperfusion, we further detected beclin-1 and LC3 expression in the hippocampal regions. Beclin-1 is the mammalian ortholog of yeast Atg6/Vps30, which plays an important role in autophagosome formation. As shown in Figure 1B and E, the expression of beclin-1 elevated gradually after ischemia/ reperfusion. Although no remarkable up-regulation was identified at the time point of $6 \mathrm{~h}$, the expression of beclin- 1 increased significantly at $12 \mathrm{~h}$ and peaked at $24 \mathrm{~h}$ of reperfusion. LC3 is the ortholog of Atg8 in mammals, which exists in two forms. When autophagy is activated, more LC3-I is converted to LC3-II; then the ratio of LC3-II/LC3-I increases ${ }^{21}$. In our study, the LC3-II/LC3-I ratio elevated significantly at 12 and $24 \mathrm{~h}$ after ischemia (Figure 1C and 1F). The time course of LC3-II/LC3-I ratio was similar to that of beclin-1 expression, which provided reliable evidence of post-ischemic autophagy activation.

\section{ME2 inhibited post-ischemic autophagy activation}

In order to investigate the effect of HIF-1 $\alpha$ up-regulation in post-ischemic autophagy activation, we administrated 2ME2 to animal models half an hour before ischemia. Compared with sham group, the expression of HIF- $1 \alpha$ increased significantly in DMSO group at 12 and $24 \mathrm{~h}$ of reperfusion as expected. While 2ME2 could remarkably inhibit the up-regulation of HIF-1 $\alpha$ at the same time points (Figure 2A and 2D).

Moreover, we examined beclin-1 and LC3 expression in each group. In the DMSO group, the expression of beclin-1 and the ratio of LC3-II/LC3-I increased significantly at the time points of 12 and $24 \mathrm{~h}$ of reperfusion. However, when post-ischemic upregulation of HIF-1 $\alpha$ was inhibited by $2 \mathrm{ME} 2$, the expression of beclin-1 and the ratio of LC3-II/LC3-I declined remarkably in the 2ME2 group at the time points of 12 and $24 \mathrm{~h}$, compared with the DMSO group (Figure 2B, 2C, 2E, 2F).

To elucidate the possible mechanism between HIF-1 $\alpha$ downregulation and autophagy inhibition after $2 \mathrm{ME} 2$ administration, we further examined P53 and BNIP3 expression in the 2ME2 and the DMSO group. Through Western blot, we demonstrated that P53 expression increased significantly after ischemia/ reperfusion. While 2ME2 remarkably inhibited P53 highexpression, compared with DMSO group (Figure 3A and 3C). In ischemic models, BNIP3 expression was up-regulated at both transcription and protein level. After 2ME2 administration, highexpression of BNIP3 was inhibited significantly (Figure 3B, 3D and $3 \mathrm{E})$. 
A
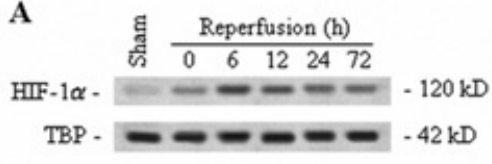

D

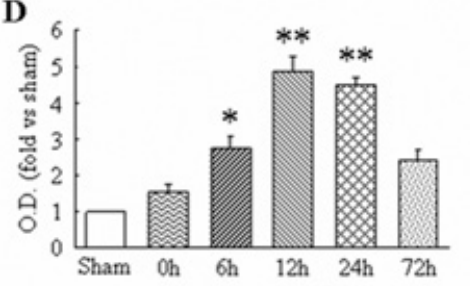

B

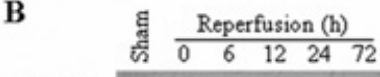

Beclin-1 - $=-10-10 \mathrm{kD}$

B-actin- $=-0-23 \mathrm{kD}$

E

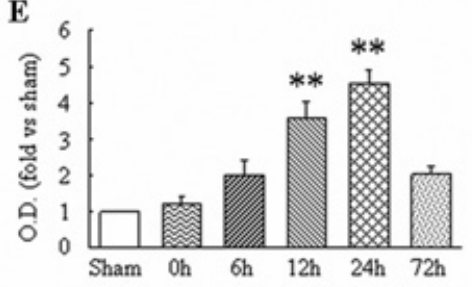

C $\quad$ ह $\frac{\text { Reperfusion }(\mathrm{h})}{0}$

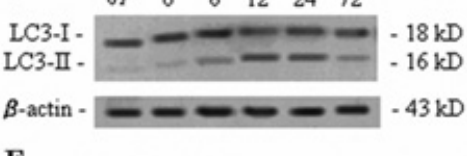

$\mathbf{F}$

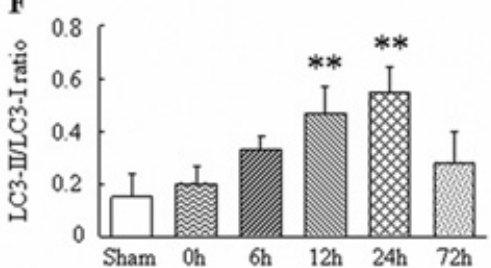

Figure 1: Western blot analysis of HIF-1 $\alpha$, beclin-1, and LC-3 expression in the hippocampal region at different time points (sham, 0, 6, 12, 24, 72 $h$ ) after global ischemia/reperfusion. A) Time course of HIF-1 a protein expression. B) Time course of beclin-1 protein expression. C) Time course of LC3II/LC3-I ratio. D) Bar graph of HIF-1 a protein expression. E) Bar graph of beclin-1 protein expression. F) Bar graph of LC3-II/LC3-I ratio. Bands were scanned and the optical density (O.D.) was represented as fold versus sham group $(D, E)$ or LC3-II versus LC3-I (F). Values are expressed as means \pm S.E.M. from five independent animals $(n=5) . * p<0.05$ versus sham group, $* * p<0.01$ versus sham group.

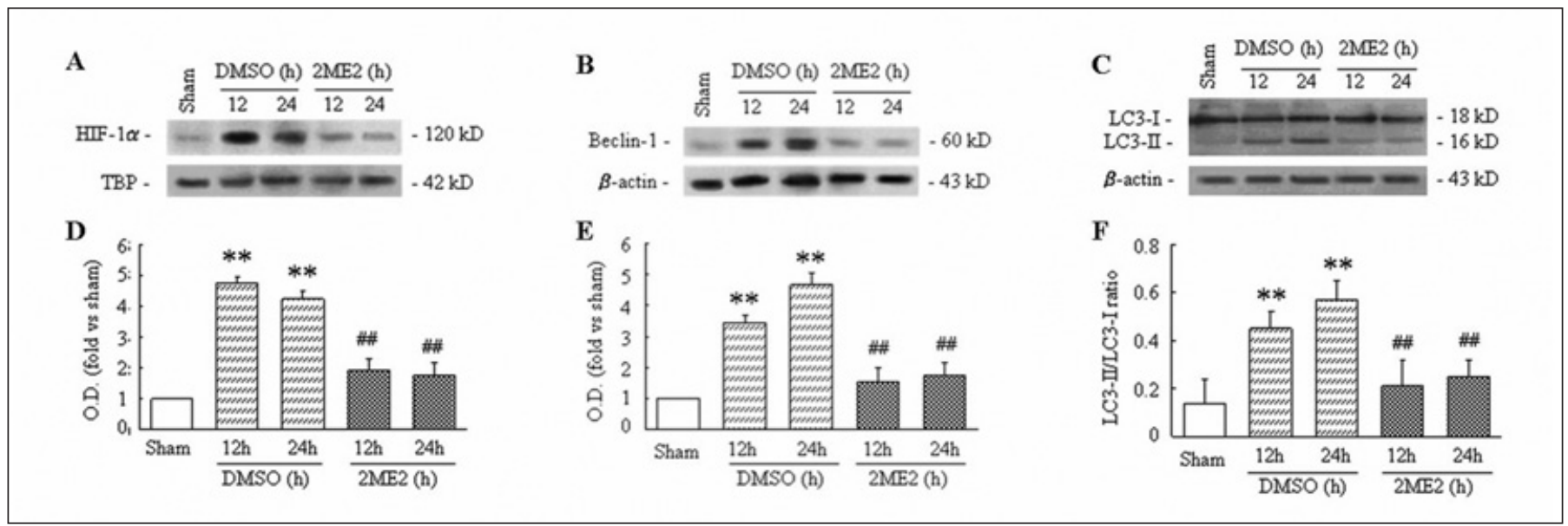

Figure 2: Effects of $2 M E 2$ on HIF-1 $\alpha$, beclin-1, and LC-3 expression in the hippocampal region after global ischemia/reperfusion. Protein levels were detected through Western blot analysis. A) HIF-1 $\alpha$ protein expression. B) Beclin-1 protein expression. C) LC3-II/LC3-I ratio. D) Bar graph of HIF-1 $\alpha$ protein expression. E) Bar graph of beclin-1 protein expression. F) Bar graph of LC3-II/LC3-I ratio. Bands were scanned and the optical density (O.D.) was represented as fold versus sham group $(D, E)$ or LC3-II versus LC3-I $(F)$. Values are expressed as means $\pm S$.E.M. from five independent animals $(n=5) . * * p<0.01$ versus sham group, \# \# $<0.01$ versus DMSO group.

\section{ME2 and 3-MA attenuated post-ischemic neuronal death}

To further elucidate the possible relationship between autophagy activation and post-ischemic neuronal injury, histology analysis was performed after $15 \mathrm{~min}$ ischemia/5 days reperfusion in animal models. The surviving cells of CA1 pyramidal neurons were calculated through cresyl violet staining. As shown in Figure 4, normal cells showed round and pale stained nuclei. The shrunken cells with pyknotic nuclei after reperfusion were counted as dead cells. Compared with sham group (Figure 4A and 4F), severe cell death was identified in both vehicle groups, including DMSO group (Figure 4B and 4G) and saline group (Figure 4D and 4I). However, 2ME2 administration could obviously minimize ischemia/reperfusion- induced neuronal degeneration (Figure $4 \mathrm{C}$ and $4 \mathrm{H}$ ), as well as those identified in 3-MA group (Figure 4E and 4J). The numbers of surviving pyramidal cells in the CA1 region of the sham group, DMSO group, 2ME2 group, saline group, and 3-MA group were $188.6 \pm 15.6,41.3 \pm 20.4,122.1 \pm 16.2,45.2 \pm 22.1$ and $138.1 \pm 19.3$, respectively (Figure $4 \mathrm{~K}$ ). Results of TUNEL staining indicated that $2 \mathrm{ME} 2$ did not increase the number of TUNEL positive cells compared with DMSO group (Figure 5).

\section{Discussion}

In the present study, we mainly examined the effects of 2ME2, a natural HIF-1 $\alpha$ inhibitor, on post-ischemic autophagy activation. Our results demonstrated that 1) global cerebral 


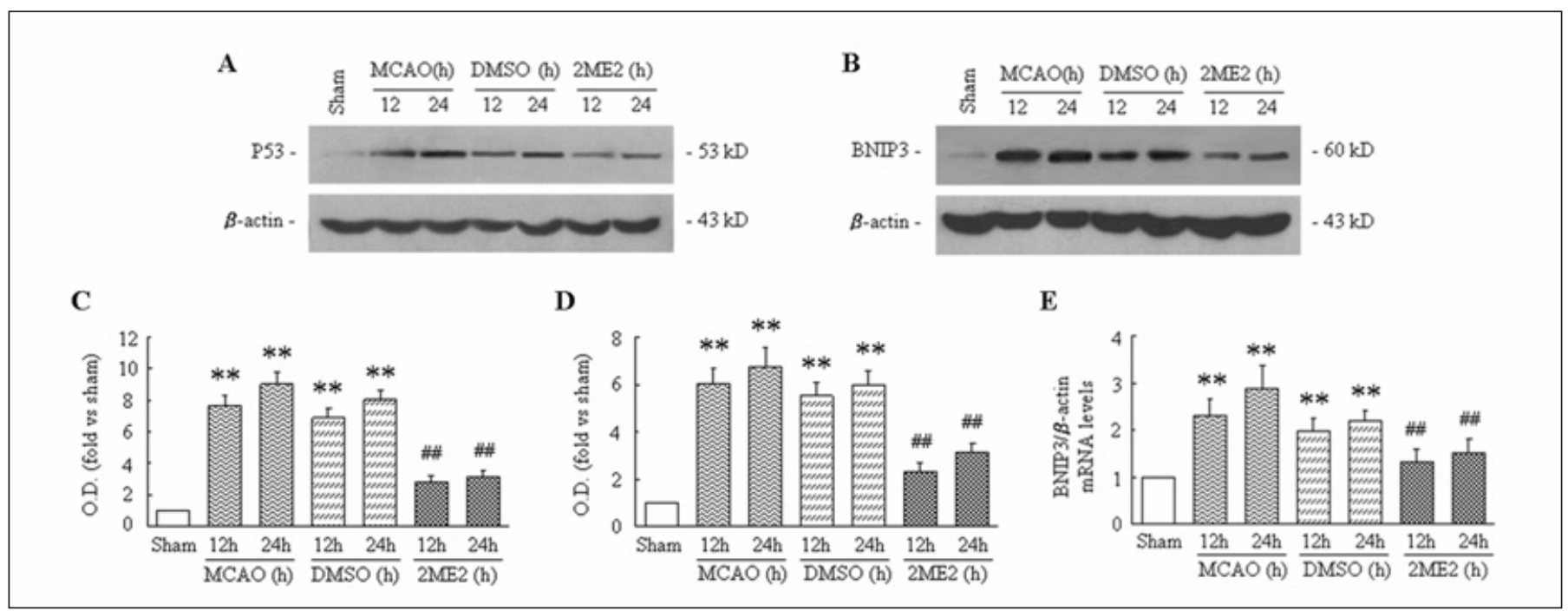

Figure 3: Effects of 2ME2 on p53 and BNIP3 expression in the hippocampal region after global ischemia/reperfusion. Protein levels were detected through Western blot analysis. BNIP3 mRNA levels were evaluated by real-time quantitative RT-PCR. A) p53 protein expression. B) BNIP3 protein expression. C)Bar graph of p53 protein expression. D) Bar graph of BNIP3 protein expression. E) Bar graph of BNIP3 mRNA levels. Bands were scanned and the optical density (O.D.) was represented as fold versus sham group $(C, D)$. Values are expressed as means $\pm S . E . M$. from five independent animals $(n=5) . * * p<0.01$ versus sham group, \# \# $p<0.01$ versus DMSO group.

ischemia could induce autophagy activation in the hippocampal region; 2) HIF-1 $\alpha$ inhibitor $2 \mathrm{ME} 2$ might decrease post-ischemic autophagy activities; 3) inhibiting autophagy helped to reduce neuronal death after ischemia/reperfusion. Our study for the first time explored the possible relationship between HIF-1 $\alpha$ upregulation and autophagy activation in vivo.

The 4-VO model described by Pulsinelli is now widely used to create global ischemia, which selectively impairs hippocampus and its surrounding structures ${ }^{22}$. As demonstrated in previous studies ${ }^{23,24}$, we also identified rapid and sustained HIF$1 \alpha$ up-regulation in vulnerable region after cerebral ischemia. However, HIF-1 $\alpha$ induction has different temporal profiles depending on the type of experimental models. After transient focal ischemia, a biphasic activation of HIF-1 $\alpha$ was identified, which peaked at $6 \mathrm{~h}$ and 6 days respectively ${ }^{23}$; While in cardiac arrest/resuscitation rats, the high expression of HIF- $1 \alpha$ in the cortex lasted from $1 \mathrm{~h}$ after ischemic injury until 7 days later ${ }^{24}$. Another previous investigation also suggested that the age of experimental animals might influence the pattern of HIF- $1 \alpha$ expression after ischemic insults in brain ${ }^{25}$. In our study using the 4-VO model in adult rats, HIF-1 $\alpha$ protein expression increased as early as $6 \mathrm{~h}$ after ischemia and peaked at the time point of $12 \mathrm{~h}$. Our results were basically in accordance with previous study using a similar model ${ }^{26}$. We proposed that the temporal profiles of HIF-1 $\alpha$ expression related not only to the duration and severity of ischemic damage, but also to the nature of impaired tissues.

HIF- $1 \alpha$ is a master regulator of oxygen homeostasis. Meanwhile, HIF-1 $\alpha$ may also serve as an important pro-death factor through interacting with tumor suppressor gene p53. In our study, we demonstrated that HIF- $1 \alpha$ up-regulation might induce p53 stabilization; in contrast, when the expression of
HIF-1 $\alpha$ was inhibited by 2ME2, p53 was down-regulated. Several previous reports have provided evidence that p53 participated in autophagy activation. For example, the inhibition of p53 could reduce tumor necrosis factor $\alpha$ (TNF- $\alpha)$-induced autophagy activation in vitro ${ }^{27}$; in excitotoxic rat models, induction of p53 contributed to the increase of autophagy activities $^{28}$. Therefore, in the present study, we supposed that HIF-1 $\alpha$ induced p53 stabilization was an important reason contributing to the post-ischemic autophagy activation.

BNIP3 is an important member of HIF-1 $\alpha$ target genes. Our results confirmed that HIF-1 $\alpha$ up-regulation after global ischemia might increase both transcription and protein expression of BNIP3. Our results were in accordance with previous findings ${ }^{13,16}$. In 2ME2 group, BNIP3 expression was correspondingly down-regulated when HIF-1 $\alpha$ was inhibited. As revealed before, BNIP3 might competes with beclin-1 for binding to bcl-2, thus freeing beclin-1 to trigger autophagy ${ }^{29}$. We supposed that BNIP3 high-expression as a result of postischemic HIF-1 $\alpha$ up-regulation was also an important mechanism for autophagy activation after cerebral ischemia. Other strong evidence for BNIP3 participating in autophagy activities included that knockdown of BNIP3 might reduce autophagic cell death under conditions of nutrient deprivation, as demonstrated previously ${ }^{30}$.

As a known HIF-1 $\alpha$ inhibitor, 2ME2 has been already evaluated in several clinical trials for cancer patients. According to previous experimental studies performing in adult rats ${ }^{16}$, $5 \mathrm{mg} / \mathrm{kg} 2 \mathrm{ME} 2$ was administrated half an hour before ischemia. Our results supported that this dosage of $2 \mathrm{ME} 2$ could remarkably inhibit post-ischemic up-regulation of HIF-1 $\alpha$. Moreover, we also identified that 2ME2 significantly decreased autophagy activities following cerebral ischemia. Provided that 

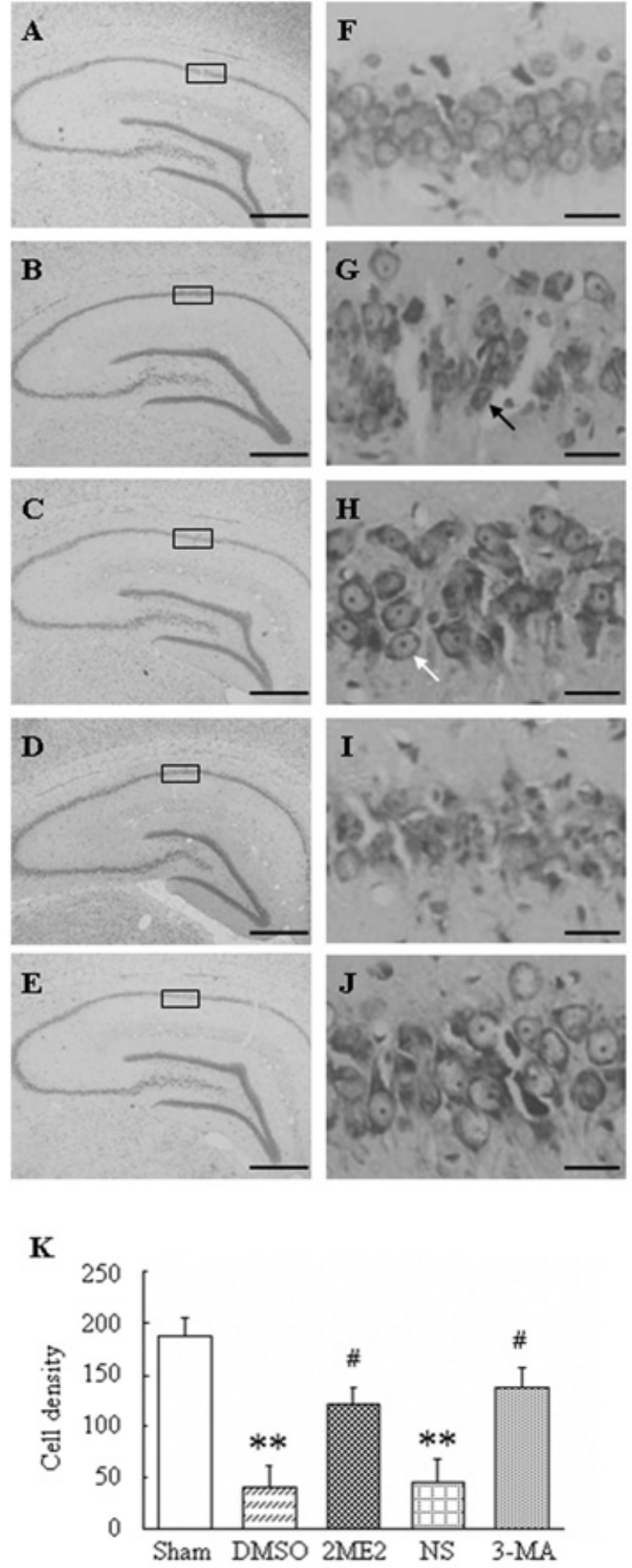

Figure 4: 2ME2 and 3-MA reduced hippocampal neuronal death after 15 min ischemia/5 days reperfusion. Compared with sham group $(A, F)$, neuronal density decreased significantly in DMSO group $(B, G)$ and saline group $(D, I)$. While $2 M E 2(C, H)$ and 3-MA $(E, J)$ remarkably rescued post-ischemic neuronal death compared to the corresponding vehicle controls. Cell density was expressed as the number of cells per 1 $\mathrm{mm}$ length of the CA1 pyramidal cells counted under a light microscope $(\times 400)(K)$. Values are presented as mean $\pm S D(n=5)$. Scale bars $=400$ $\mu m(A-E) ; 10 \mu m(F-J)$. White arrow indicated normal cell; black arrow indicated pyknotic cell. $* * p<0.01$ versus sham group, $\# p<0.05$ versus corresponding vehicle controls.
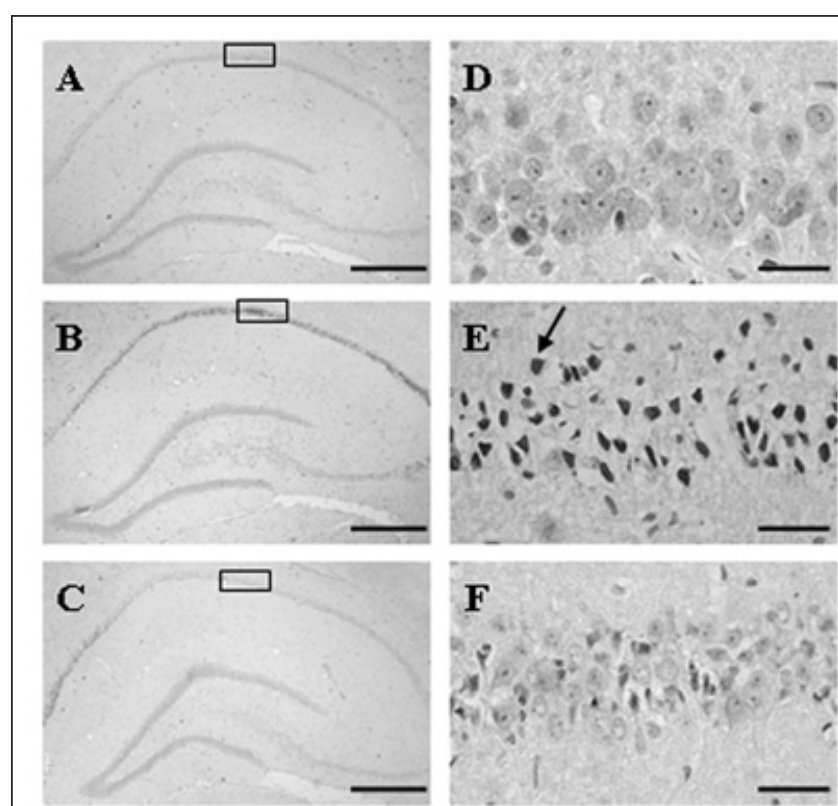

G

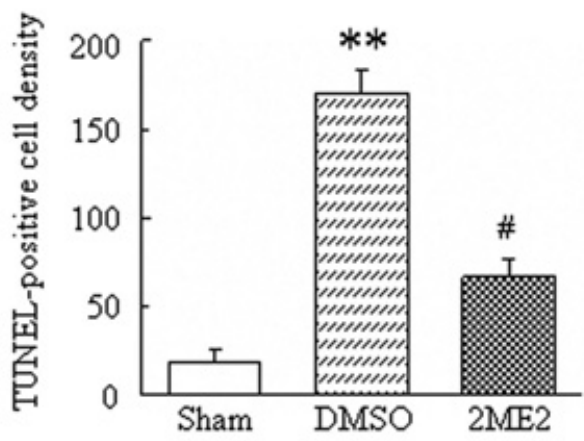

Figure 5: 2ME2 reduced hippocampal TUNEL-positive cells after 15 min ischemia/5 days reperfusion. Compared with sham group $(A, D)$, TUNEL-positive cell density increased significantly in DMSO group $(B$, $E)$. While $2 M E 2(C, F)$ remarkably reduced post-ischemic TUNELpositive cell density in the hippocampal CA1 region compared to DMSO group. Cell density was expressed as the number of cells per $1 \mathrm{~mm}$ length of the CA1 pyramidal cells counted under a light microscope $(\times 400)(G)$. Values are presented as mean $\pm S D(n=5)$. Scale bars $=400 \mu \mathrm{m}(A-C)$; $10 \mu m(D-F)$. Black arrow indicated TUNEL-positive cell. $* * p<0.01$ versus sham group, \# $p<0.05$ versus DMSO group. 
HIF-1 $\alpha$ might contribute to autophagy activation through stabilizing p53 and promoting BNIP3 transcription, we supposed that 2ME2 probably down-regulated autophagy activities through inhibiting post-ischemic HIF-1 $\alpha$ up-regulation. By means of TUNEL staining, our study suggested that $2 \mathrm{ME} 2 \mathrm{did}$ not increase apoptotic cell death when inhibiting autophagy in global ischemia models. These findings provided forceful evidence that 2ME2 actually rescued neurons rather than pushing them from type-II to type-I cell death. Our investigation, combined with previous studies, indicated that not only early administration of 2ME2 after cererbral ischemia but also prophylactic administration of 2ME2 before cerebral ischemia could protect neurons from post-ischemic damage ${ }^{16,31}$. Since 2ME2 might induce cell death in cancer therapy, discrepancy of 2ME2 effects in cancer and cerebral ischemia exists. An important reason responsible for the discrepancy might be the complex role that HIF-1 and its down-stream molecules play in different diseases. To date, over 60 genes have been identified as HIF-1 target genes, which participate in a broad range of cellular physiological or pathophysiological activities. In cancer, chronic hypoxic conditions induce sustained expression of HIF-1, the main role of which is to promote cancer cell proliferation, survival and invasion ${ }^{32}$. Therefore, $2 \mathrm{ME} 2$ has been proved to be a promising anti-cancer compound by inhibiting HIF-1. In cerebral ischemia, acute severe hypoxic insult induces the expression of cell death-related HIF-1 target genes soon after ischemia $^{16,31}$. Thus, prophylactic or post-ischemic early administration of 2ME2 might protect neurons from ischemiainduced neuronal injury.

As those identified in focal cerebral ischemia models ${ }^{10}$, our study confirmed that autophagy participated in post-ischemic neuronal injury. Beclin-1 expression and LC3-II/LC3-I ratio increased significantly as early as $12 \mathrm{~h}$ after ischemia, peaked at $24 \mathrm{~h}$, and continued to be high until $48 \mathrm{~h}$ of reperfusion. It should be noted that the peak of autophagy activation was a little later than that of HIF- $1 \alpha$ expression. These findings were in accordance with our speculation that HIF-1 $\alpha$ might be correlative to autophagy activation through activating p53 and BNIP3. As revealed in our results, inhibiting autophagy, either by direct inhibitor 3-MA or by indirect inhibitor 2ME2, might prevent pyramidal neuron death after ischemia. Therefore, these findings provided powerful evidence that autophagy could be a potential target for post-ischemic neuronal protection.

\section{CONClusions}

In summary, our study suggested that 2ME2 inhibited autophagy activation following cerebral ischemia, probably through the HIF-1 pathway; therefore, 2ME2 could attenuate post-ischemic neuronal damage through autophagy inhibition. Further studies focusing on the accurate mechanisms of HIF-1 influencing autophagy activities after cerebral ischemia are still needed.

\section{ACKNOWLEDGEMENTS}

This study was funded by the Science and Technology Commission of Shanghai Municipality (03DZ19702, 06JC14052) and Shanghai Key Discipline Program (S30202). Authors Xiao$\mathrm{Yu}$ Xin and Jing Pan contributed equally to this article.

\section{REFERENCES}

1. Lopez AD, Mathers CD, Ezzati M, Jamison DT, Murray CJ. Global and regional burden of disease and risk factors, 2001: systematic analysis of population health data. Lancet. 2006; 367(9524): 1747-57.

2. Gutiérrez M, Merino JJ, de Leciñana MA, Díez-Tejedor E. Cerebral protection, brain repair, plasticity and cell therapy in ischemic stroke. Cerebrovasc Dis. 2009;27 Suppl 1:177-86.

3. Candelario-Jalil E. Injury and repair mechanisms in ischemic stroke: considerations for the development of novel neurotherapeutics. Curr Opin Investig Drugs. 2009;10(7): 644-54.

4. Chong ZZ, Maiese K. Targeting WNT protein kinase B, and mitochondrial membrane integrity to foster cellular survival in the nervous system. Histol Histopathol. 2004;19(2):495-504.

5. Gill MB, Perez-Polo JR. Hypoxia ischemia-mediated cell death in neonatal rat brain. Neurochem Res. 2008;33(12):2379-89.

6. Balduini W, Carloni S, Buonocore G. Autophagy in hypoxiaischemia induced brain injury: evidence and speculations. Autophagy. 2009:5(2):221-3.

7. Reggiori F, Klionsky DJ. Autophagy in the eukaryotic cell. Eukaryot Cell. 2002;1(1):11-21.

8. Shintani T, Klionsky DJ. Autophagy in health and disease: a double-edged sword. Science. 2004; 306(5698):990-5.

9. Adhami F, Liao G, Morozov YM, et al. Cerebral ischemia-hypoxia induces intravascular coagulation and autophagy. Am J Pathol. 2006;169(2):566-83.

10. Rami A, Langhagen A, Steiger S. Focal cerebral ischemia induces upregulation of Beclin 1 and autophagy-like cell death. Neurobiol Dis. 2008;29(1):132-41.

11. Nakayama K. Cellular signal transduction of the hypoxia response. J Biochem. 2009;146(6):757-65.

12. Tanaka T, Wakamatsu T, Daijo H, et al. Persisting mild hypothermia suppresses hypoxia- inducible factor-1alpha protein synthesis and hypoxia-inducible factor-1-mediated gene expression. Am J Physiol Regul Integr Comp Physiol. 2010;298(3):R661-71.

13. Bruick RK. Expression of the gene encoding the proapoptotic Nip3 protein is induced by hypoxia. Proc Natl Acad Sci USA. 2000;97 (16):9082-7.

14. Ricker JL, Chen Z, Yang XP, Pribluda VS, Swartz GM, Van Waes C. 2-methoxyestradiol inhibits hypoxia-inducible factor 1alpha, tumor growth, and angiogenesis and augments paclitaxel efficacy in head and neck squamous cell carcinoma. Clin Cancer Res. 2004;10(24):8665-73.

15. Mabjeesh NJ, Escuin D, LaVallee TM, et al. 2ME2 inhibits tumor growth and angiogenesis by disrupting microtubules and dysregulating HIF. Cancer Cell. 2003;3(4):363-75.

16. Chen C, Hu Q, Yan J, et al. Multiple effects of 2ME2 and D609 on the cortical expression of HIF-1alpha and apoptotic genes in a middle cerebral artery occlusion- induced focal ischemia rat model. J Neurochem. 2007;102(6):1831-41.

17. Zhou D, Matchett GA, Jadhav V, Dach N, Zhang JH. The effect of 2-methoxyestradiol, a HIF-1 alpha inhibitor, in global cerebral ischemia in rats. Neurol Res. 2008;30(3):268-71.

18. Becker CM, Rohwer N, Funakoshi T, et al. 2-methoxyestradiol inhibits hypoxia-inducible factor- 1 alpha\} and suppresses growth of lesions in a mouse model of endometriosis. Am J Pathol. 2008;172(2):534-44.

19. Pulsinelli WA, Brierley JB. A new model of bilateral hemispheric ischemia in the unanesthetized rat. Stroke. 1979;10(3):267-72.

20. Lowry $\mathrm{OH}$, Rosebrough NJ, Farr AL, Randall RJ. Protein measurement with the Folin phenol reagent. J Biol Chem. 1951; 193(1):265-75.

21. Mizushima N, Yoshimori T. How to interpret LC3 immunoblotting. Autophagy. 2007;3(6):542-5.

22. Pan J, Pei DS, Yin XH, Hui L, Zhang GY. Involvement of oxidative stress in the rapid Akt1 regulating a JNK scaffold during ischemia in rat hippocampus. Neurosci Lett. 2006;392(1-2):47-51 .

23. Baranova O, Miranda LF, Pichiule P, Dragatsis I, Johnson RS, Chavez JC. Neuron-specific inactivation of the hypoxia inducible factor 1 alpha increases brain injury in a mouse model of transient focal cerebral ischemia. J Neurosci. 2007;27(23): 6320-32. 
24. Pichiule P, Agani F, Chavez JC, Xu K, LaManna JC. HIF-1 alpha and VEGF expression after transient global cerebral ischemia. Adv Exp Med Biol. 2003;530:611-7.

25. Chen W, Jadhav V, Tang J, Zhang JH. HIF-1alpha inhibition ameliorates neonatal brain injury in a rat pup hypoxic-ischemic model. Neurobiol Dis. 2008;31(3):433-41.

26. Jin KL, Mao XO, Nagayama T, Goldsmith PC, Greenberg DA. Induction of vascular endothelial growth factor and hypoxiainducible factor-1alpha by global ischemia in rat brain. Neuroscience. 2000;99(3):577-85.

27. Cheng Y, Qiu F, Tashiro S, Onodera S, Ikejima T. ERK and JNK mediate TNFalpha-induced p53 activation in apoptotic and autophagic L929 cell death. Biochem Biophys Res Commun. 2008;376(3):483-8.

28. Wang Y, Dong XX, Cao Y, et al. p53 induction contributes to excitotoxic neuronal death in rat striatum through apoptotic and autophagic mechanisms. Eur J Neurosci. 2009;30(12):2258-70.
29. Mazure NM, Pouysségur J. Atypical BH3-domains of BNIP3 and BNIP3L lead to autophagy in hypoxia. Autophagy. 2009;5(6): 868-9.

30. Bellot G, Garcia-Medina R, Gounon P, et al. Hypoxia- induced autophagy is mediated through hypoxia-inducible factor induction of BNIP3 and BNIP3L via their BH3 domains. Mol Cell Biol. 2009;29(10):2570-81.

31. Yeh SH, Ou LC, Gean PW, Hung JJ, Chang WC. Selective inhibition of early-but not late-expressed HIF-1 $\alpha$ is neuroprotective in rats after focal ischemic brain damage. Brain Pathol. 2010; Sep 30. doi: 10.1111/j.1750-3639.2010.00443.x. [Epub ahead of print]

32. Mooberry SL. Mechanism of action of 2-methoxyestradiol: new developments. Drug Resist Updat. 2003;6(6):355-61. 